\title{
Does Zero-COVID neglect health disparities?
}

\author{
Nancy S Jecker (10), 1,2 Derrick K S Au ${ }^{2}$
}

\begin{abstract}
${ }^{1}$ School of Medicine, Department of Bioethics \& Humanities, University of Washington, Seattle, Washington, USA ${ }^{2}$ CUHK Centre for Bioethics, The Chinese University of Hong Kong Faculty of Medicine, Shatin, New Territories, Hong Kong
\end{abstract}

\section{Correspondence to} Dr Nancy S Jecker, School of Medicine, Department of Bioethics \& Humanities, University of Washington, Seattle, WA 98195, USA; nsjecker@uw.edu

Received 23 July 2021 Accepted 11 November 2021

Check for updates

(C) Author(s) (or their employer(s)) 2021. No commercial re-use. See rights and permissions. Published by BMJ.

To cite: Jecker NS, Au DKS. $J$ Med Ethics Epub ahead of print: [please include Day Month Year]. doi:10.1136/ medethics-2021-107763

\begin{abstract}
Since the World Health Organization (WHO) first declared the novel coronavirus a pandemic, diverse strategies have emerged to address it. This paper focuses on two leading strategies, elimination and mitigation, and examines their ethical basis. Elimination or 'Zero-COVID' dominates policies in Pacific Rim societies. It sets as a goal zero deaths and seeks to contain transmission using stringent short-term lockdowns, followed by strict find, test, trace and isolate methods. Mitigation, which dominates in the US and most European nations, sets targets for community transmission and lifts restrictions once targets are met. This approach takes calculated risks and regards a certain amount of disease and death as ethically justified. Section I examines different societal responses to risk that underlie these different policy approaches. Section II focuses on ethical arguments favouring Zero-COVID and raises health equity objections. Section III proposes a long-term strategy that balances the twin goals of promoting population health and health equity.
\end{abstract}

Since the WHO first declared the novel coronavirus a pandemic, diverse strategies have emerged to address it. This paper focuses on two leading strategies, elimination and mitigation, and examines their social and ethical bases. We apply a health equity lens and find fault with both approaches but focus on Zero-COVID, which fares worse by this measure. We propose a long-term strategy that better balances the twin goals of population health and health equity.

Elimination or 'Zero-COVID' dominates Pacific Rim societies, such as New Zealand, Australia, Singapore, Japan, South Korea, Vietnam, mainland China, Hong Kong and Taiwan, many of which are island states that can more readily seal their borders. It is framed as setting zero deaths as a goal and reaching this by forcefully containing transmission through short-term lockdowns, followed by stringent find, test, trace and isolate methods. It emphasises a duty to protect lives at all costs. Early in the pandemic, countries applying elimination were often the most successful at preventing transmission, leading some to conclude that elimination was an optimal strategy in terms of both saving lives and minimising economic damage. ${ }^{1}$

Mitigation dominates the US and most European nations. It is framed as 'flattening the curve' and avoiding overwhelming healthcare systems by setting targets for community transmission and imposing restrictions on individuals to reduce spread until targets are met. It takes calculated risks, regarding a certain amount of disease and death as ethically justified, although unfortunate.

With the advent of highly effective vaccines, vaccination has become a dominant factor for combatting SARS-CoV-2, just as it was historically in the push to eradicate other infectious diseases. Yet it seems likely vaccination alone will not prove adequate, and non-pharmacologic methods will continue to be considered as a longer-term strategy. If global vaccine distribution continues to favour high-income and upper middle-income nations, the first phase of recovery might begin in wealthier regions. A second phase might occur when vaccines reach the rest of the world. During a final, postpandemic phase, deaths from the novel coronavirus may recede worldwide, with SARS-CoV-2 reappearing annually alongside $\mathrm{H} 1 \mathrm{~N} 1$ and other respiratory viruses, such as rhinovirus, coronavirus, respiratory syncytial virus and parainfluenza, referred to as the 'common cold'. The timing of these phases is hard to gauge, and the trajectory may not be linear. If the general characterisation is roughly right, societies may never realise the elusive 'Zero-COVID' but may nonetheless reduce the severity and incidence of the novel coronavirus to a level resembling diseases like diphtheria, tetanus, measles, mumps, rubella and Haemophilus influenzae.

While neither Zero-COVID nor mitigation can remove the inequitable impact of the COVID-19 pandemic on socially disadvantaged groups, each could do more to address it. Both policies focus narrowly on preserving capacity in the acute care system (in countries that have them) in contrast to previous pandemic planning which emphasised overall population health. We focus on the health equity effects of Zero-COVID, which have been less thoroughly explored. Section I examines different societal responses to risk that underlie each approach. Section II explores ethical arguments favouring Zero-COVID and argue strict Zero-COVID fares poorly as a long-term strategy. Section III proposes a long-term strategy that better promotes population health and health equity.

\section{RESPONSES TO RISK}

Risk is an unavoidable feature of everyday life. We assume risks each time we take a swim, get in a car or cross the street. We also assume risks by not doing certain things-exercising, sleeping enough or eating right. When we stop to think about risks we take, they may seem worth it because of what they enable us to do, namely, live our lives and enjoy fuller, more flourishing lives. Risk-taking can advance societal goods like public safety, as well as personal well-being. Yet what risks are worth taking? What goods are essential for living and leading a flourishing life? In some parts of the world, people accept more risks to health because they perceive this enables them to live and lead better lives, freer from outside encumbrances. In these societies, mitigation strategies might be more appealing. In other 
societies, protecting life and health are by far the weightiest values, and more restrictions seem worth it because they safeguard these precious goods. While risk is a quotidian feature of daily life, proclivities towards risk are shaped by a society's collectivist or individualist values, tighter or looser attitudes toward rules, recent experiences with public health threats, and changing conditions.

\section{Collectivist or Individualist}

While all policy choices involve calculated risks, collectivist and individualist values have been shown to influence societal response to risk by affecting how people perceive decisions, formulate options and select actions. ${ }^{2}$

In more collectivist societies, people tend to see themselves as inseparably joined with others and part of a wider social fabric. This inclines them to perceive risks as affecting everyone in their interconnected group and to minimise risks to protect others. One way of elaborating this is in terms of face, a standard designating positive social self-worth in relation to a social network. Face has Chinese origins, derived from liăn, indicating society's confidence in a person's moral character, and miànzi, indicating amoral social prestige society awards based on a person's performance. ${ }^{34}$ Concerns about saving face, losing face, and maintaining face affect what people do and the risks they are willing to take to varying degrees. ${ }^{5}$

In collectivist societies, face consciousness may be expressed as a sense of collective duty or taking pride in reflecting well on behalf of one's group. For example, Confucian-influenced societies, like mainland China, Vietnam, North Korea and Taiwan, are collectively oriented and inclined to regard saving face as a duty owed others. The appeal of Zero-COVID policies for these societies is that they fulfil a duty owed to others not to become sickened by disease. Japanese society displays a similar concern with maintaining face for others' benefit (referred to as seken-tei) and avoiding the loss of face associated with becoming sick. ${ }^{6}$ Preserving face by staying healthy is entwined with traditional Shinto notions, such as kegare, an impure and unclean condition which is associated with disease and death. By staying well and avoiding disease, people perceive they can save face and preserve seken-tei.

People in individualist-oriented societies, such as the USA and some, but not all, ${ }^{7}$ European nations, show less face consciousness. They tend to regard individuals as independent and self-sufficient-free to 'do their own thing'. This leads to making decisions based mostly on individual preferences, while deflecting efforts to restrict individual choice. The appeal of mitigation strategies in individualist societies is that they seem to interfere less with people's autonomous choice. Even though personal decisions, such as not wearing face coverings, can threaten others' health and safety, individuals may downplay such risks and feel entitled to be self-determining.

\section{Tight or loose}

A further factor shaping risk response is a tight or loose attitude toward rules. Gefland et al asked people in 33 nations a series of questions, including 'Are there many social norms that people in your society are supposed to follow?' 'Are there very clear expectations for how people should act in most situations? and 'If someone acts inappropriately, will others strongly disapprove? ${ }^{8}$ They discerned patterns in the responses people gave. In some societies, which they called, 'tight', people reported strong norms and low tolerance for deviant behaviour and characterised their socialisation as limiting the range of acceptable behaviours; in other societies, which they called 'loose', people reported fewer norms and greater tolerance for deviant behaviour and described their socialisation as broadening the range of permissible behaviours.

These characterisations shed light on different responses to SARS-CoV-2. Tighter societies were generally more accepting of and compliant with strict rules requiring sheltering in place, testing, and contract tracing; this led to lower COVID-19 death rates early in the pandemic. Looser societies generally resisted restrictions and opted for less stringent strategies like mitigation; this resulted in higher COVID-19 death rates overall. With the emergence of more dangerous virus variants and the availability of highly effective vaccines in wealthier regions, tightness and looseness continue to shape pandemic responses, with relatively tight societies generally slower to reopen and relatively loose societies generally resuming prepandemic ways of life sooner. Many other factors shape societies' tightness or looseness, including politics, policing power, wealth and technological capabilities.

\section{Historical experience}

A further factor shaping societal responses to risk are recent public health threats. Generally, 'societies evolve to be tighter when they face chronic threats over the course of many years,' and they tighten up in the face of a sudden collective threateven if it is short-lived. ${ }^{9}$ Unless a threat persists or recurs, societies revert to a prior state, suggesting that inertial forces influence tightness and looseness, yet are malleable.

A recent experience that might have impacted risk response during the COVID-19 pandemic was the 2003 SARS epidemic, which affected over 24 Asian nations. SARS might have increased risk aversion in affected nations, inclining people towards stricter elimination strategies and risk-protective behaviours, like sheltering in place. By contrast, nations without such experiences were not driven by a collective memory to respond in this way.

\section{Changing conditions}

As conditions change and people reflect on new experiences, risk perceptions and policy choices can shift. Since the SARSCoV-2 virus first emerged, the virus has become a more formidable foe. Hypertransmissible mutations, like Delta, reduce the odds of realising the elusive 'Zero-COVID'; with some experts estimating that $90 \%$ of a population would require vaccination to achieve population-level protection. ${ }^{10}$

Other changes include rapid roll-out of highly effective vaccines. Since most shots to date have gone to high-income and upper middle-income countries, the novel coronavirus seems unlikely to be eradicated through vaccination alone. Even after vaccines are widely available, vaccine refusal may persist and variants of concern may emerge that reduce vaccine efficacy, leading societies to consider non-pharmacologic methods as a long-term strategy.

If SARS-CoV-2 becomes endemic, societies pursuing ZeroCOVID will be forced to change policy goals and decide what level of increase in background death rates is acceptable. The 1918 pandemic caused the deaths of 50 million people before receding, now returning annually during 'influenza season' to claim the lives of about 650000 people. The transition to a possibly prolonged phase of COVID-19 will require societies to decide when it becomes tenable to resume ordinary life, despite predictable increases in death and disease. These developments inform our assessment of ethical arguments for and against Zero-COVID. 


\section{ETHICAL ARGUMENTS}

\section{Arguments for Zero-COVID}

A central argument to justify Zero-COVID holds that societies have an overarching duty to protect life and regards every death from COVID-19 as one too many. Since Zero-COVID has a better track record of saving lives than mitigation, we should favour it. Evidence that Zero-COVID saves more lives comes from multiple studies comparing countries using elimination and mitigation; for example, Oliu-Barton found countries adopting Zero-COVID-19 had COVID-19 death rates 25 times lower. $^{11}$

In response, while suppression tactics reduce COVID-19 related deaths, they inadvertently increase deaths from other causes. Woolf et al reported $72.9 \%$ of increased death rates in the USA between March 2020 and January 2021 were directly or indirectly attributable to COVID-19. ${ }^{12}$ Other studies document excess death during shelter-in-place orders from domestic violence, ${ }^{13}$ depression-related suicide ${ }^{14}$ and drug overdose. ${ }^{15}$ Advocates for Zero-COVID might reply by saying that their approach saves more lives overall, even if it yields some excess deaths. Yet, once we begin to think about trade-offs this way, we are moving away from a duty-based argument towards utilitarian type reasoning.

Utilitarian defences of Zero-COVID regard it as the best means to maximise well-being for everyone affected. Since inequities in the distribution of well-being can themselves be a source of negative utility, a more sophisticated utilitarian might count inequities as negative utilities and minimise them to the extent necessary to maximise overall well-being. However, this approach may remain vulnerable to some health equity objections, including those requiring giving all people equal chances to live ${ }^{16}$ or requiring preventing inequalities that subvert people's status as free and equal persons. ${ }^{17}$

\section{Arguments against Zero-COVID}

Arguments opposing Zero-COVID appeal more directly to health equity and a special duty to disadvantaged members of society. These arguments may apply differently depending on a country's level of wealth. In low-income countries, policies like lockdowns produce particularly adverse consequences, because many people are reliant on daily wages to survive and lack the means to purchase food in advance and refrigerators to store it. Commenting on this, a leading group of African intellectuals called the 'containment' model of northern countries 'brutal' for most Africans; they demanded politicians consider the 'chronic precarity' that characterises the daily lives of their people and stressed 'the value of every human being regardless of status.' 18 The crux of their argument was that the poor should not be consigned to die from starvation to reduce death rates from COVID-19. This lesson was learnt previously, during the Ebola epidemic in Sierra Leone, when lockdowns led to inhumane health and social consequences for vulnerable groups. ${ }^{19}$

In both low-income and high-income countries, health equity considerations relate to structural inequalities, like income inequality and racism. Consider Singapore. Lauded early in the pandemic by Harvard epidemiologist, Lipsitch, as a 'gold standard' due to its rapid public health response and success containing SARS-CoV-2, ${ }^{20}$ Singapore's success unravelled in April 2020, when the virus reached migrant worker dormitories. Human Rights Watch reported Singapore's migrants were 'housed in crowded and unsanitary dormitories with up to 20 people sharing a room, and communal bathrooms... conditions that increased the risk of spreading COVID-19;' during lockdown, the bulk of migrants were confined to 'hot, overcrowded rooms with little ventilation, leaving them at risk of infection. ${ }^{21}$ By August 2020, over 90\% of Singapore's reported cases were among dormitory residents. The case of Singapore illustrates how forces other than face consciousness impact the risks people consider when making policy decisions.

Singapore is hardly alone. Many wealthy nations pursuing elimination jeopardised the health and safety of displaced and marginalised people. For example, while Hong Kong is a wealthy city, it is among the most unequal places in the world, with one in five people living in poverty. ${ }^{22}$ During lockdowns, over 200000 individuals in the city of Hong Kong were forced to retreat to spaces, locally referred to as 'cage homes', where the average living space is 48 square feet, less than one-third the size of a New York City parking space, with ethnic minorities hit hardest. ${ }^{23}$ Like Singapore, Hong Kong's poverty is entwined with ethnicity. South Asians, (a group including Indians, Pakistanis and Nepalese) experience higher poverty rates than the general population; more than half $(56.5 \%)$ Hong Kong Pakistanis live below the poverty line. ${ }^{24}$ How these groups fared under lock-down measures has not been studied, but we suspect they did not fare well.

The examples of low-income African countries, migrant workers in Singapore and people living in poverty in Hong Kong reflect a broader pattern of poor COVID-19 outcomes associated with poverty, poor housing conditions and limited access to healthcare. They demonstrate health equity concerns so serious and morally offensive that they cast serious doubt on elimination as an ethically sustainable way forward. The persistent use of elimination is even more ethically problematic than its shortterm application, because it embeds inequities deeper and more permanently, raising stakes for disenfranchised groups.

While we have underlined that Zero-COVID responses raises troublesome health equity concerns, health equity concerns are hardly confined to this strategy. Mitigation can also disproportionately burden marginalised communities, especially when they occur against a backdrop of structural racism or poverty. For example, in the USA, where mitigation prevails, black and brown communities fared worse as did people residing in areas with high social vulnerability; mitigation policies did little to alleviate these inequitable effects. ${ }^{25}$ A larger point worth making is that when public health focuses on a single disease, overall population health suffers, as do core public health values, like equity, solidarity and justice.

\section{A WAY FORWARD}

The best long-term response to the SARS-CoV-2 virus balances eliminating disease with promoting population health and health equity. It considers what is owed groups that are unduly burdened by COVID-19 and by societal responses to it. First, it imposes restrictions proportionate with a group's socioeconomic level and resources. For example, low-income groups in Africa, migrant workers in Singapore, and 'cage people' in Hong Kong might be subject to mask mandates and the means to comply supplied. The ethical justification is that society has a duty to protect its least well-off members and to make amends for dipropionate burdens they bore from societal policies. Second, a balanced approach tailors restrictions to real risks in a population, applying more restrictions to subgroups at greater risk of severe disease and death, while also paying attention to equity. For example, it imposes fewer restrictions on vaccinated than unvaccinated groups after vaccines are widely and equitably available. The ethical rationale is that societies ought to use the least restrictive means necessary to achieve public health 
goals. To avoid burdensome effects on marginalised groups, this approach requires qualification. For example, before vaccines were available, policies barring visitors from long-term care facilities serving older clientele might avoid unduly burdening older people by developing ways to visit outdoors, limit visitors, and require masking. Third, a balanced approach assigns different priorities to different domains. For example, schools merit higher priority for opening than gyms, because young children without in-person schooling miss crucial socialdevelopmental milestones. Lifting 'no visitor' policies in hospitals merits higher priority too, because families can serve as a lifeline for hospitalised patients. The ethical rationale is the utilitarian view that more serious, long lasting, and irreversible harms count more. Finally, a balanced approach shares risk fairly. It enforces restrictions in ways that are non-stigmatising and safeguard basic needs for all citizens. The ethical basis is respecting human dignity.

In conclusion, two leading strategies for responding to COVID-19 fall short. Zero-COVID is the most prone to neglect health disparities, but mitigation also falters when it loses sight of overall population health. We propose a long-term strategy that puts twin aims of health equity and population health front and centre.

Acknowledgements The views expressed are the authors' own and do not reflect the official position of the Chinese University of Hong Kong Centre for Bioethics. Part I is adapted from 2 op-eds pieces: N.S. Jecker, 'Is the Zero-Covid Approach of China and Japan About Saving Face?'(South China Morning Post, 23 June 2021) and D.K.S. Au, 'Long-Term Zero-Covid Strategy Raises Questions' (Hong Kong Economic Journal, 19 July 2021).

Collaborators Not applicable.

Contributors Each author contributed substantially to the conception and analysis of the work; drafting the work or revising it critically; final approval of the version to be published and is accountable for all aspects of the work. NS Jecker is the guarantor, responsible for the overall content and accepts full responsibility for the finished work and decision to publish.

Funding The authors have not declared a specific grant for this research from any funding agency in the public, commercial or not-for-profit sectors.

Competing interests None declared.

Patient consent for publication Not applicable.

Provenance and peer review Not commissioned; externally peer reviewed.

Data availability statement There are no data available for this work.

This article is made freely available for use in accordance with BMJ's website terms and conditions for the duration of the covid-19 pandemic or until otherwise determined by BMJ. You may use, download and print the article for any lawful, non-commercial purpose (including text and data mining) provided that all copyright notices and trade marks are retained.
ORCID iD

Nancy S Jecker http://orcid.org/0000-0002-5642-748X

\section{REFERENCES}

1 Baker MG, Wilson N, Blakely T. Elimination could be the optimal response strategy for covid-19 and other emerging pandemic diseases. BMJ 2020;371.

2 Guess CD. Decision making in Individualistic and Collectivist cultures. International association of cross-cultural psychology. Online Readings in Psychology and Culture 2004; $4(1)$

$3 \mathrm{HC} \mathrm{H}$. The Chinese Concepts of 'Face'. American Anthropological Association 1944;46(1):45-64.

4 DY H. On the concept of face. American Journal of Sociology 1976:81(4):867-84.

5 Weber EU, Hsee CK. Modeling cross-cultural differences in risk taking. Psychonomic Bulletin \& Review 1999;6(4):611-7.

6 Jecker NS, Takahashi S. Shaming and Stigmatizing healthcare workers in Japan during the COVID-19 pandemic. Public Health Ethics 2021;14(1):72-8.

7 Rainsack B, Buyx A. Solidarity: Reflections on an Emerging Concept in Bioethics. Nuffield Council on Bioethics, 2011.

8 Gelfand MJ, Raver JL, Nishii L, et al. Differences between tight and loose cultures: a 33-nation study. Science 2011;332(6033):1100-4.

9 Gefland MJ. Rule makers, rule breakers. How tight and loose culture wire our world. Scribner, 2018: 66.

10 Fauci A. Quoted in McNeil dG, how much herd immunity is enough? New York times, 2021: 2 .

11 Oliu-Barton M, Pradelski BSR, Aghion P, et al. SARS-CoV-2 elimination, not mitigation, creates best outcomes for health, the economy, and civil liberties. Lancet 2021;397(10291):2234-6.

12 Woolf SH, Chapman DA, Sabo RT, et al. Excess deaths from COVID-19 and other causes in the US, March 1, 2020, to January 2, 2021. JAMA 2021;325(17):1786-9.

13 Das M, Das A, Mandal A. Examining the impact of lockdown (due to COVID-19) on domestic violence (dv): an evidences from India. Asian J Psychiatr 2020;54:102335.

14 Banerjee D, Kosagisharaf JR, Sathyanarayana Rao TS. 'The dual pandemic' of suicide and COVID-19: A biopsychosocial narrative of risks and prevention. Psychiatry Res 2021;295(9):1113577.

15 Appa A, Rodda LN, Cawley C, et al. Drug overdose deaths before and after Shelterin-Place orders during the COVID-19 pandemic in San Francisco. JAMA Netw Open 2021;4(5):e2110452.

16 Taurek JM. Should the numbers count? Philos Public Aff 1977;6(4):293-316.

17 Anderson ES. What is the point of equality? Ethics 1999;109(2):287-337.

18 Soyinka Wet al. Open Letter from African Intellectuals to Leaders over Covid-19. Al Jazeera, 2020.

19 Saalim K, Sakyi KS, Tuz-Zohra F. Reported health and social consequences of the COVID-19 pandemic on vulnerable populations and implemented solutions in six West African countries: a media content analysis. PLoS One 2021;16(6):e0252890.

20 Lipsitch M. Coronavirus (COVID-19): press conference with Marc Lipsitch, 2020. Available: https://www.hsph.harvard.edu/news/features/coronavirus-covid-19-pressconference-with-marc-lipsitch-03-04-20/

21 Human Rights Watch. World report 2021: Singapore, 2021. Available: https://www. hrw.org/world-report/2021/country-chapters/singapore\#

22 Government of the Hong Kong Special Administrative Region, Census and Statistics Department. Poverty situation report 2019; 2018: 34.

23 Wang V, May T. In 'Coffin Homes' and 'Cages, ' Hong Kong Lockdown Exposes Inequality. New York Times, 2021.

24 Government of the Hong Kong Special Administrative Region,, Census and Statistics Department,. Poverty situation report on ethnic minorities, 2018: 17.

25 U.S. Centers for Disease Control and Prevention (CDC). Health equity considerations and racial and ethnic minority groups, 2021. Available: https://www.cdc.gov/ coronavirus/2019-ncov/community/health-equity/race-ethnicity.html 